\title{
Large mobile aortic thrombus (MAT) and the role of imaging in urgent selection for invasive treatment
}

\author{
Wioletta Sacharczuk', Rafał Dankowski', Aleksander Drogowski², Michał Monkiewicz², Andrzej Szyszka' \\ ${ }^{1} 2^{\text {nd }}$ Department of Cardiology, Poznan University of Medical Sciences, Poznań, Poland \\ 2John Paul II Hospital, Poznań, Poland
}

\author{
Correspondence to: \\ Wioletta Sacharczuk, MD, PhD, \\ $2^{\text {nd }}$ Department of Cardiology, \\ Poznan University of Medical \\ Sciences, \\ 28 Czerwca 1956 St. 194, \\ 61-485 Poznań, Poland \\ phone: +48666940 480, \\ e-mail: \\ wioletta.sacharczuk@wp.pl \\ Copyright by the Author(s), 2022 \\ DOI: 10.33963/KP.a2021.0192 \\ Received: \\ December 20, 2021 \\ Accepted: \\ December 28, 2021 \\ Early publication date: \\ December 29, 2021
}

A 49-year-old female was admitted to the hospital after a loss of consciousness preceded by motor aphasia. Transient cerebral ischemia was diagnosed. She was a hypertensive, heavy smoker, and was taking hormone replacement therapy. The differential diagnosis of systemic embolism was started. The suprasternal view of the echocardiographic examination showed a hyperechoic, mobile structure of $20 \mathrm{~mm}$ in length in the ascending aorta (Figure $1 \mathrm{~B}$, the blue arrow; Supplementary material, Video S1). Computed tomography (CT) angiography confirmed the mobile aortic thrombus (MAT) located proximally to the brachiocephalic trunk (Figure 1A). Computed tomography scan showed neither enlargement of the aortic diameter nor damage to the aortic wall (Figure 1C-E). The CT orthogonal and sagittal projections were used in MAT dimensioning. The irregular-surfaced structure, $18 \mathrm{~mm}$ long (Figure 1D, the yellow arrow) and $10 \mathrm{~mm}$ wide, was visualized (Figure 1E, the red arrow). The large size and cauliflower shape of the MAT indicated a high potential for embolism. The patient was urgently referred for open aortic surgery. During the procedure, the thrombus moved to the left upper limb, confirming its high embolic potential. An $18 \mathrm{~mm}$-long thrombus was removed from the left brachial artery. The aorta looked healthy without any damage and residual lesions. In the follow-up, no further embolic events were observed. The patient was given a prophylactic dose of aspirin and statins, and she was advised to quit smoking. Hormone replacement therapy was discontinued. Periodic echocardiography was recommended.
The presence of mobile thrombus in a healthy aorta (MAT) is relatively rare. The pathophysiology of MAT is unclear, as thrombotic states are uncommon. In many cases, MAT can be the source of systemic, life-threatening embolisms such as myocardial infarction, cerebral or limb embolization [1]. Although clinical consequences of MAT are serious and may affect a patient's prognosis, there are still no clear guidelines on therapeutic strategies [1-3]. Thus the treatment strategy should be individualized in every case. Three therapeutic goals should be taken under consideration: target anticoagulation therapy, surgical thrombectomy in the treatment of embolic complications, and endovascular/open surgery to remove the primary aortic thrombus $[4,5]$. Invasive treatment should be dedicated to patients with high embolic potential and a low risk of surgery complications. In this case, imaging was crucial in assessing the embolic potential of MAT and selecting an urgent invasive treatment strategy.

\section{Supplementary material}

Supplementary material is available at https:// journals.viamedica.pl/kardiologia_polska.

\section{Article information \\ Conflict of interest: None declared.}

Open access: This article is available in open access under Creative Common Attribution-Non-Commercial-No Derivatives 4.0 International (CC BY-NC-ND 4.0) license, allowing to download articles and share them with others as long as they credit the authors and the publisher, but without permission to change them in any way or use them commercially. For commercial use, please contact the journal office at kardiologiapolska@ptkardio.pl. 


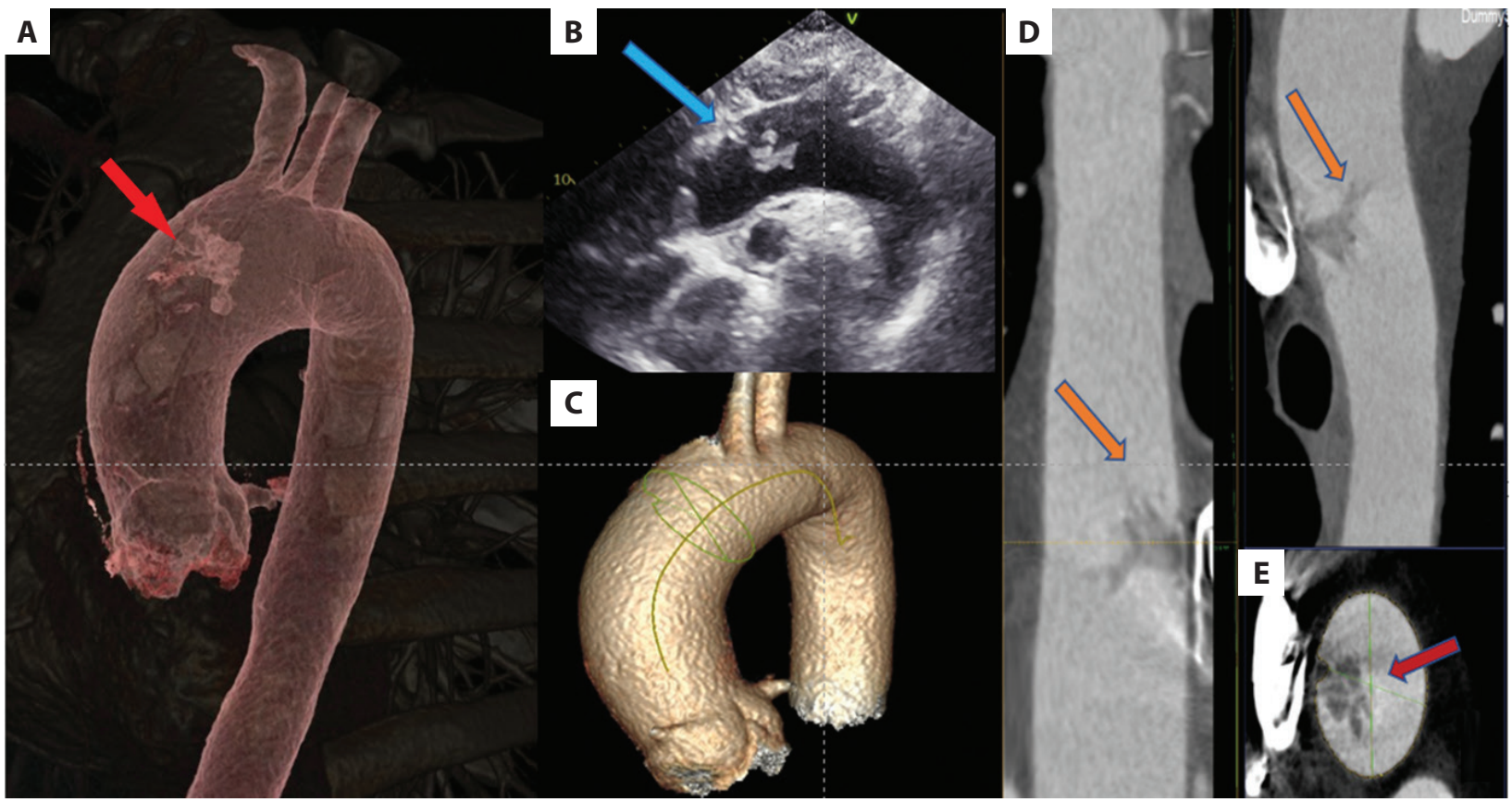

Figure 1. A. A computed tomography 3D scan with visualization of a mobile aortic thrombus (MAT) in the ascending aorta (the red arrow). B. Two-dimensional echocardiographic suprasternal long-axis (sagital) view presenting $20 \mathrm{~mm}$ MAT within the ascending aorta (the blue arrow). C. Computed tomography - a 3D scan showing the size of the aorta, excluding other aortic wall pathologies. D, E. Computed angiography, perpendicular and sagittal projections showing the irregular surface structure of the MAT: $18 \mathrm{~mm}$ long (D, the yellow arrows) and $10 \mathrm{~mm}$ wide (E, the red arrow)

\section{REFERENCES}

1. Varino J, Rodrigues R, Pereira B, et al. Aortic mural thrombus [article in Portuguese]. Rev Port Cir Cardiotorac Vasc. 2019; 26(1): 19-26, indexed in Pubmed: 31104372.

2. Cañadas V, Vilacosta I, Luaces M, et al. Thrombosis of an apparently normal thoracic aorta and arterial embolism [article in Spanish]. Rev Esp Cardiol. 2008; 61(2): 196-200, indexed in Pubmed: 18364189.

3. Erbel R, Aboyans V, Boileau C, et al. ESC Committee for Practice Guidelines. 2014 ESC Guidelines on the diagnosis and treatment of aortic diseases: Document covering acute and chronic aortic diseases of the thoracic and abdominal aorta of the adult. The Task Force for the Diagnosis and Treatment of Aortic Diseases of the European Society of Cardiology (ESC). Eur Heart J. 2014;35(41):2873-2926, doi: 10.1093/eurheartj/ehu281, indexed in Pubmed: 25173340.

4. Weiss $S$, Bühlmann R, von Allmen RS, et al. Management of floating thrombus in the aortic arch. J Thorac Cardiovasc Surg. 2016; 152(3): 810-817, doi: 10.1016/j.jtcvs.2016.03.078, indexed in Pubmed: 27160939.

5. Fayad ZY, Semaan E, Fahoum B, et al. Aortic mural thrombus in the normal or minimally atherosclerotic aorta. Ann Vasc Surg. 2013; 27(3): 282-290, doi: 10.1016/j.avsg.2012.03.011, indexed in Pubmed: 22929167. 